\title{
Fear learning triggers structural changes at GABAergic synapses in the basal amygdala
}

\author{
Yu Kasugai ${ }^{1}$, Markus Hauschild ${ }^{2}$, Werner Sieghart ${ }^{3}$, Ryuichi Shigemoto ${ }^{4}$, Nicolas Singewald ${ }^{2}$, Francesco Ferraguti ${ }^{{ }^{*}}$ \\ From 16th Scientific Symposium of the Austrian Pharmacological Society (APHAR) \\ Vienna, Austria. 25-27 November 2010
}

\section{Background}

In Pavlovian fear conditioning, in which initially a conditioned stimulus (CS) is repeatedly paired with an aversive stimulus (US), animals learn to associate CS with US, hence attaching emotional significance to sensory stimuli. Conditioned fear can be suppressed when the CS is repeatedly presented alone, a phenomenon known as fear extinction. Previous studies suggest that the mechanisms underlying fear conditioning involve inhibitory neurotransmission through $\mathrm{GABA}_{\mathrm{A}}$ receptors. $\mathrm{GABA}_{\mathrm{A}}$ receptors are generally composed of two $\alpha$, two $\beta$ and one $\gamma$ subunits. Sixteen $\mathrm{GABA}_{\mathrm{A}}$ receptor subunits have been identified in mammals, which indicates that these receptors may have multiple biophysical and pharmacological properties. Recent work showed that fear conditioning induces a dramatic downregulation of benzodiazepine binding sites and transcripts for gephyrin and some $\mathrm{GABA}_{\mathrm{A}}$ receptor subunits in the basal nucleus of the amygdala (BA), which were restored to control levels after fear extinction.

\section{Methods}

In this work, we analysed by means of the freeze-fracture replica immunolabelling technique (SDS-FRL) the synaptic and extrasynaptic content of the $\mathrm{GABA}_{\mathrm{A}}-\gamma 2$ subunit in the BA of C57BL/6 mice that underwent fear conditioning as well as extinction. Using this technique, we could also measure the full synaptic area of GABAergic synapses. Immunogold particles for $G_{A B A}$ subunits tend to concentrate in clusters of intramembrane particles (IMP) on the protoplasmic face of the plasma membrane, indicating that labelled IMP clusters represent GABAergic synapses.

\footnotetext{
* Correspondence: francesco.ferraguti@i-med.ac.at

${ }^{1}$ Department of Pharmacology, Innsbruck Medical University, 6020 Innsbruck, Austria

Full list of author information is available at the end of the article
}

\section{Results}

The average size of GABAergic synapses in control mice was $0.030 \pm 0.019 \mu \mathrm{m}^{2}(\mathrm{n}=223)$. The mean synaptic size $\left(0.040 \pm 0.025 \mu \mathrm{m}^{2}, \mathrm{n}=198\right)$ in fear conditioned animals was significantly ( $<<0.0001$, one-way ANOVA) increased, whereas in mice that underwent extinction it returned to values similar to those of controls $(0.032 \pm$ $\left.0.021 \mu \mathrm{m}^{2}, \mathrm{n}=154\right)$. The distribution frequency of the area of GABAergic synapses was also found to be significantly different between fear conditioned and control mice $(\mathrm{p}<0.01)$. The labelling density for the $\mathrm{GABA}_{\mathrm{A}}-\gamma 2$ subunit was significantly lower in both synaptic ( $\mathrm{p}<0.05$, Kruskal-Wallis) and extrasynaptic $(\mathrm{p}<0.05$, Kruskal-Wallis) areas in fear conditioned animals. However, the decrease in synaptic density appears to be a consequence of the increased synaptic area.

\section{Conclusions}

These results suggest that in normal animals fear conditioning produces an enlargement of GABAergic synapses maintaining the number of $\mathrm{GABA}_{\mathrm{A}}$ receptors substantially unaltered.

\section{Author details}

'Department of Pharmacology, Innsbruck Medical University, 6020 Innsbruck, Austria. ${ }^{2}$ Department of Pharmacology and Toxicology, Institute of Pharmacy, University of Innsbruck, 6020 Innsbruck, Austria. ${ }^{3}$ Department of Biochemistry and Molecular Biology, Medical University of Vienna, 1090 Vienna, Austria. ${ }^{4}$ Division of Cerebral Structure, National Institute for Physiological Sciences, Okazaki, Aichi, 444-8585, Japan.

Published: 16 November 2010

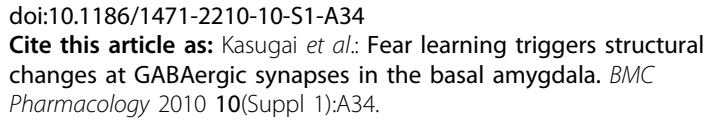

